\title{
Halley Research Station, Antarctica: calving risks and monitoring strategies
}

\author{
R. Anderson, D. H. Jones, and G. H. Gudmundsson \\ British Antarctic Survey, High Cross, Madingley Road, Cambridge, UK
}

Correspondence to: G. H. Gudmundsson (ghg@bas.ac.uk)

Received: 16 October 2013 - Published in Nat. Hazards Earth Syst. Sci. Discuss.: 5 November 2013

Revised: - Accepted: 23 February 2014 - Published: 17 April 2014

\begin{abstract}
The British Antarctic Survey's Halley Research Station is located on the Brunt Ice Shelf, Antarctica, where it is potentially vulnerable to calving events. Existing historical records show that the Brunt Ice Shelf is currently extended further into the Weddell Sea than it was before its last large calving event, so a new calving event may be overdue. We describe three different possible future scenarios for a largescale calving event on Brunt Ice Shelf. We conclude that currently the most threatening scenario for the Halley Research Station is a calving event on the neighbouring StancombWills Glacier Tongue, with subsequent detrimental consequences for the stability of the Brunt Ice Shelf. Based on available data, we suggest an increasing likelihood of this scenario occurring after 2020. We furthermore describe ongoing monitoring efforts aimed at giving advanced warning of an imminent calving event.
\end{abstract}

\section{Introduction}

The Halley Research Station, operated by the British Antarctic Survey, has been located on the Brunt Ice Shelf (BIS) in Antarctica since 1956 (Hemmen, 2010). The first Halley station was built at the conclusion of the International Geophysical Year Trans-Antarctic Expedition, and its location was determined by the end point of this expedition.

Since 1956, the base has grown from a simple wooden hut (Halley I) to a series of linked, ski-mounted, relocatable modules (Halley VI). A staff of 10-20 occupy the base year-round, with up to 100 present in the austral summer. The research station has a primary focus on atmospheric sciences, and is the site for many long-term monitoring data sets including the records that first indicated the existence of the Antarctic ozone hole (Farman et al., 1985).

Due to its location on a floating ice shelf (see Fig. 1), the Halley Research Station is subjected to particular hazards, a large calving event being the most serious and obvious example. Here we give an overview of different possible future calving scenarios and describe ongoing monitoring activities aimed at detecting any increase in risk and allowing for advanced warning of any potential calving events.

Halley has been rebuilt six times since the start of operations in 1956. Although calving has always been a threat to the Halley Research Station, it has never been the primary reason for a rebuild. With $1 \mathrm{~m}$ of snow accumulating annually, buildings are eventually buried and must be abandoned. Of the first four stations, Halley IV was occupied the longest (12 years, from 1972 to 1984), because its steel tubing construction was designed to withstand burial.

Halley V was built upon steel legs that could be jacked up, making it possible to keep raising the Halley V buildings above the snow surface. However, its subsurface infrastructure had become unsafe. Its replacement, Halley VI, was opened for science operations in January 2012.

As with all large ice shelves in Antarctica, the BIS is continuously supplied with ice flowing from the continent. The surface mass balance of BIS is positive (King et al., 1996), and the mass loss of the BIS therefore is predominantly caused by calving (Depoorter et al., 2013). Calvingevent risks prompted the building of Halley VI closer to the mainland. At its new location, Halley VI is less likely to be lost in a calving event. Nevertheless, the possibility of such an event, even at its new location, clearly cannot be completely discounted. 


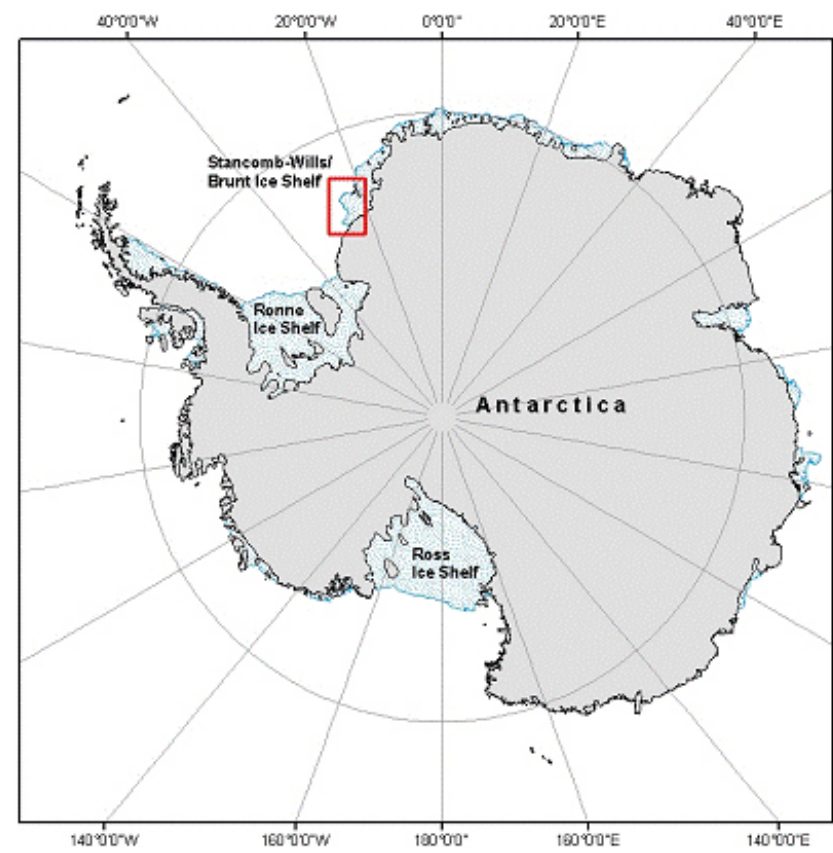

Fig. 1. The location of Brunt Ice Shelf on which the Halley Research Station is located.

Given the inherent risks associated with building on an ice shelf, Halley VI was designed to be mobile. In the event of an imminent calving event, the building can be towed to the interior of the ice shelf. However preparing for such an event requires insights into the behaviour of the ice shelf and identification of signals that could forewarn a dangerous calving event. The initial location of Halley VI is shown in Figs. 1 and 2. As this paper will demonstrate, at this location the risk of losing the station through calving is smaller. Halley VI is located inland from the McDonald Ice Rumples (MIR) (see Fig. 2) whilst still far away from the grounding line, where crevassing and undulations would create hazards in daily operations.

In this paper, we examine three possible hazards that pose a risk to the Halley Research Station: (1) a routine calving event due to long-term ice flow and deformation of the ice shelf itself, (2) a collision of an iceberg with the BIS, and (3) the calving of a neighbouring Stancomb-Wills Glacier Tongue and a subsequent collision with the BIS.

However, we shall also address other possible causes for calving, including iceberg collisions and the calving of neighbouring ice shelves.

The paper is organised as follows: we first describe the geography of the Brunt Ice Shelf (Sect. 2). We then consider different calving scenarios for Brunt Ice Shelf (Sect. 3). Data collection methods to ascertain the severity of each of these risks are described in Sect. 4, and the results are then analysed in Sect. 5. Conclusions are summarised in Sect. 6.

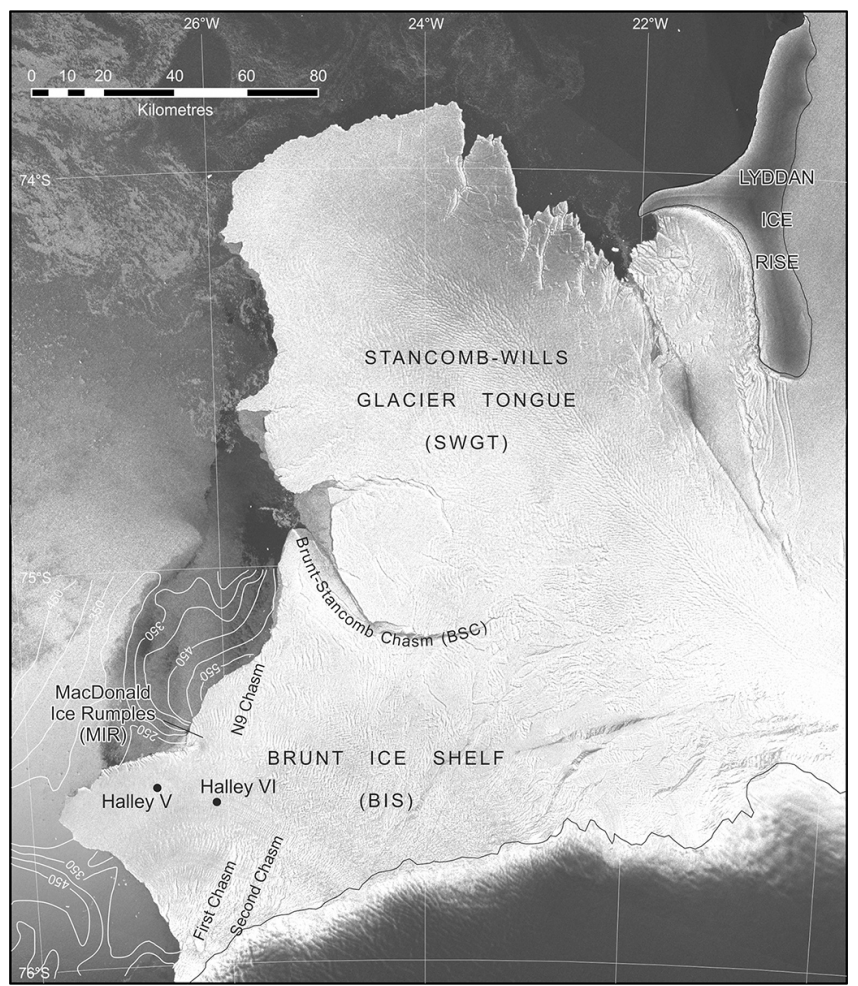

Fig. 2. Location of Halley V and Halley VI on Brunt Ice Shelf.

\section{The Brunt Ice Shelf - geography}

As shown in Fig. 2, the BIS is located at $75^{\circ} \mathrm{W}, 26^{\circ} \mathrm{S}$ in the eastern Weddell Sea. To the north-east of the BIS lies the Stancomb-Wills Glacier Tongue (SWGT), a considerably larger ice shelf than the BIS forming the seaward projections of the SW Glacier. (Despite its name, the SWGT Glacier tongue is an ice shelf, just like the Brunt Ice Shelf.) Together the two ice shelves, the BIS and SWGT, form a continuous floating ice mass and the exact boundaries between the BIS and SWGT are difficult to define. The SWGT is bounded on the north-east edge by the Lyddan Ice Rise and the RiiserLarsen Ice Shelf. The BIS is pinned along the northern margin by the McDonald Ice Rumples (see Fig. 2).

There is considerable variation found in the literature with regard to the naming of both the BIS and SWGT. Thomas (1973a), for example, refers to both the BIS and SWGT combined as Brunt Ice Shelf, and uses the term "Stancomb-Wills Promontory" for the part of the SWGT lost in a large-scale calving event sometime between 1915 and 1955 (see Fig. 7 in Thomas, 1973a). The term "Stancomb-Wills Promontory" appears to have been given originally to the SWGT by Shackleton during his 1915 expedition to this area (Shackleton, 1919).

The two ice shelves are fed from separate glaciers flowing seawards from the continent. Of these ice shelf tributaries the Stancomb-Wills Glacier is the most prominent one. As 
the ice spills across the grounding line, marking the division between the grounded and floating ice masses, large cracks and chasms are formed in the ice at several places. With time these chasms then heal and fill in as sea ice forms within them and snow drifts in from the surface. Along the northern calving front of the BIS a series of jagged "creeks" are found that result from stresses in the ice as it flows around the McDonald Ice Rumples.

The BIS has three rifts of note, named the N9 Chasm, First Chasm, and Second Chasm (shown in Figs. 2 and 11). Both the First and Second chasms formed as open cracks on the grounding line. Subsequently these cracks were filled with sea ice and snow drift. The alignment of the N9 Chasm differs to that of the other chasms and the grounding line. This, as well as the misalignment of neighbouring morphological features suggests that the N9 Chasm may have been formed by a past collision. The First and Second chasms are located between the Halley locations (both V and VI) and the grounding line. They are upstream from the McDonald Ice Rumples and appear currently to be inactive.

The N9 Chasm is an old rift that has not shown significant activity since 2003. However, in the last two decades the rift has entered the region immediately east of the McDonald Ice Rumples where a calving event occurred in 1971. This innate weakness already has an open-water region at its north end, visible in Fig. 11, which could rapidly widen into another full calving event as the strains around the McDonald Ice Rumples increase.

The other two rifts, First and Second chasms, were created by the regime change of the 1971 calving event, as observed by Halley personnel (Clark, 1986a, b) after the event. They have been inactive since. However, if such a calving event did occur again at the N9 Chasm, it may once again reactivate these other two chasms or create new ones in the region.

The SWGT also has three rifts of note, each of which have been measured and tracked with monthly satellite images in the interval 2008-2011. Particular attention has been paid to the westerly SWGT rift, which was regularly monitored to track its extension. This monitoring is described further in Sect. 3.4.

\section{Possible future calving scenarios of Brunt Ice Shelf}

Most ice-shelf calving events are minor events where smaller chunks of ice break from the edge of the ice front as the ice front advances. Due to calving, the rate of ice shelf advance is generally less than the velocity of the ice at the ice front. By contrast, a significant calving event describes a scenario where a large proportion of the ice shelf calves in a single contiguous event.

Ice-shelf calving is affected by a number of different processes. For the purpose of the following discussion we will distinguish between three different mechanisms that potentially may lead to a large-scale calving event on the BIS in

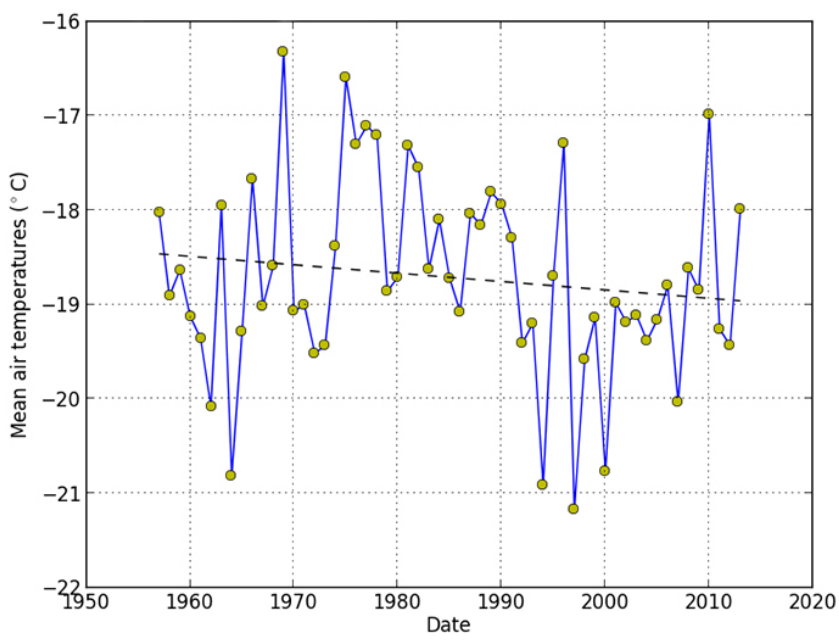

Fig. 3. Annual surface air temperatures at the Halley Research Station.

the near future: (1) progressive enlargement of cracks and chasms on the BIS due to general ice-shelf flow, (2) collision of an iceberg with the BIS causing a break-up of the ice shelf, and (3) calving of the SWGT and subsequent collision of large fragments of the SWGT with the BIS. However, we start by discounting as a possibility a large-scale ice shelf collapse of the type observed on Larsen B in early 2002.

\section{1 "Larsen-B" type calving event}

One of the most spectacular calving events in recent times took place between 31 January and 2 March 2002 on the Larsen B ice shelf, Antarctica Peninsula. About $3250 \mathrm{~km}^{2}$ of ice broke up leaving a much smaller remnant ice shelf (Rack and Rott, 2004). The disintegration of Larsen B was part of a string of large calving events that have seen the collapse or retreat of a number of large ice shelves along the Antarctic Peninsula over last 100 years. A comprehensive survey of ice shelf retreats on the peninsula can be found at (Cook and Vaughan, 2010).

Calving events such as the one leading to the collapse of Larsen B were preceded by the formation of large supraglacier meltwater ponds. It is generally accepted that surface melting facilitated the large-scale disintegration of Larsen B by allowing progressive downwards propagation of preexisting surface cracks (Holland et al., 2011; Banwell et al., 2013). On the Brunt Ice Shelf, surface temperatures are well below the freezing point throughout the year, and surface melting does not occur. The surface temperature has shown a slight decrease annually since records began in 1956 (Turner and Colwell, 2004) (see Fig. 3).

Also, the BIS and SWGT are currently much stiffer than the Larsen B ice shelf was prior to its collapse (Khazendar et al., 2009). For both reasons we can discount the possibility of a "Larsen-B" type collapse happening on either the BIS or SWGT. 


\subsection{Progressive enlargement of cracks and chasms on the BIS due to general ice-shelf flow}

As an ice shelf grows larger, the changing geometry may cause cracks to form and grow with time, potentially leading to a calving event. The extent to which an ice shelf can grow before it develops such cracks is dependent on many factors unique to each ice shelf. Factors related to geometry and the occurrence of pinning points affect location, spatial pattern, and the growth of crevasses. Each ice shelf can be expected to produce large or small, frequent or less frequent calving events, depending on local conditions and its rate of growth.

It appears reasonable to expect that large calving events on the BIS will occur repeatedly once the ice shelf has reached a certain size and shape, and that there is a "natural" calving cycle of repeated growth and loss. Historical ice-front positions provide clues to this cycle. These positions can be obtained from satellite images (Simmons and Rouse, 1984), ground surveys (Limbert, 1964), or ship charters (Worsely, 1921; Lange and Kohnen, 1985). Since 1990, ice fronts have been tracked using synthetic aperture radar (SAR) satellites. From the early 1970s, visible-band images from the Landsat satellite provided information on ice-front positions, and more recently a number of different satellite derived data sets can be used for this purpose. The last known large calving event on BIS occurred in September 1971 in the vicinity of the McDonald Ice Rumples when a large fragment of the ice shelf broke off between the 1986 and 2008 ice fronts in Fig. 4 (Thomas, 1973b).

Before the 1970s, there are three critical ice-front measurements that define our knowledge of calving history: one from 1915, and two from 1956 and 1958. Frank Worsely, on the Shackleton-led Endurance expedition in 1915, was the first to survey the SWGT and the BIS (Worsely, 1921). At this time the SWGT was at its most advanced state known (see Fig. 7) whereas the BIS appears far more retreated, as can be seen in Fig. 4. Ice-front positions were not measured again until the visit of an Argentinean ship in 1956 (Expedition, 1955). By this time the SWGT had undergone a significant calving event, with the 1956 front showing its leastadvanced known position. The BIS also displays a similar retreated state, implying calving occurred between 1915 and 1956. In 1958, the Royal Society conducted a comprehensive survey of the shelf, providing a survey-quality reliable ice-front position (IGY, 1958). This 1958 map is inconsistent with the 1956 map, but consistent with maps from subsequent surveys. For this reason the 1958 survey is used as the most retreated position of the ice front that can be trusted.

In terms of calving cycles, it is evident that significant calving occurred on the BIS between 1915 and 1956, but a specific date is difficult to ascertain. The data does not allow us to conclude if only one or several calving events occurred in this period. A summary of these data can be found in Fig. 5. This figure shows the ice-front position measured

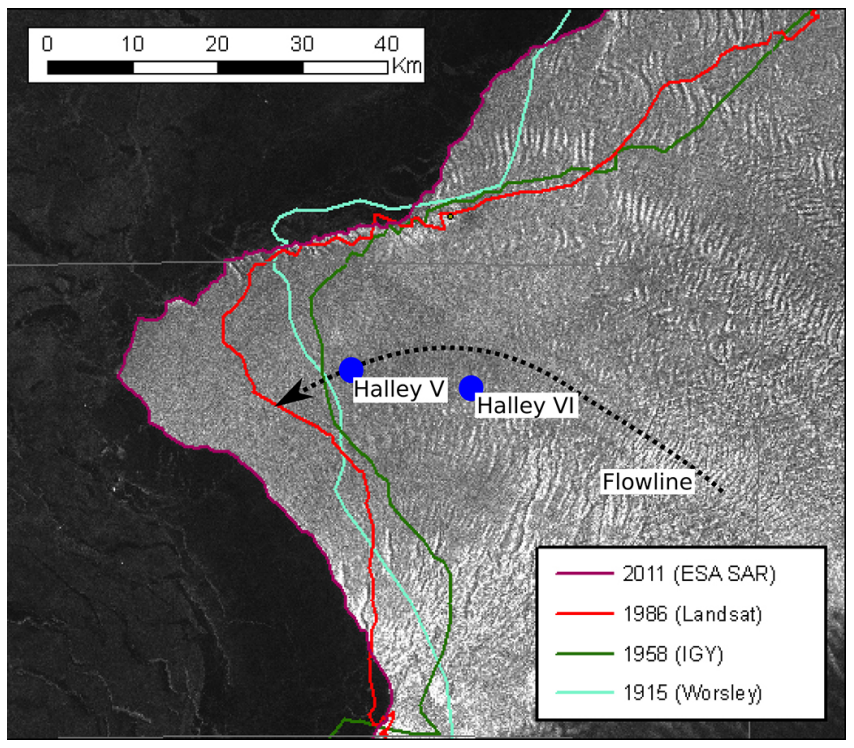

Fig. 4. A selection of historical ice fronts on the Brunt Ice Shelf (1915 position from Worsely, 1921). The unobserved period between 1915 and 1958 can be expected to have a period of growth followed by a large calving event.

along a flow line passing through the Halley V station. The solid blue line shows the known ice-front positions from 1958 to present. The slope of this line represents the longterm growth rate of the shelf. We can extrapolate it into the past from 1958. If we then fit a line of this slope through the known position from the Worsley 1915 ice front, we can represent the ambiguous period as a set of parallel lines, a "pre-calving event line" and a "post-calving event line". In this representation, a calving event would be a "jump" from the upper line to the lower line.

There are at least four notable observations to be drawn from Fig. 5 .

- Unless the rate-of-advance of the ice front was close to zero between 1915 and 1958, a possibility we can safely exclude, there must have been a large calving event at the BIS sometime between 1915 and 1958 . An identical conclusion can be reached with regard to the SWGT.

- The BIS has already grown beyond the maximal size that it could have attained had the last large calving event occurred at its maximal possible extent consistent with the data, i.e. immediately before the 1958 observations.

- At the present rate of movement $\left(470 \mathrm{~m} \mathrm{a}^{-1}\right)$, the Halley V base will in 2018 be at a location that must have been open water prior to 1958 . Indeed, if the calving event occurred anytime in the first 35 years of this 43 year gap of data, then the Halley V location would already be in formerly open water. 


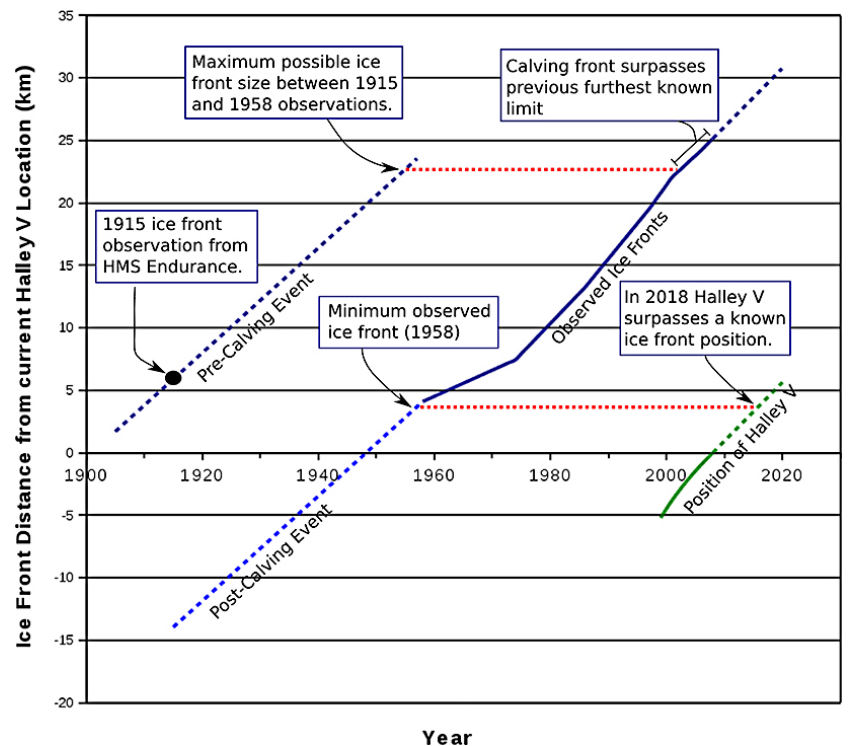

Fig. 5. Position of the BIS ice front measured as a distance along a flow line running through Halley V Research Station. The vertical axis of the figure represents distance along this flow line relative to the 2009 position of Halley V. The thick blue line is based on measured positions of the BIS ice front. The dashed blue lines represent the change in ice-front position with time assuming a constant rate of ice-front advance equal to that observed between 1958 and 2010. The dashed blue line in the upper-left part of the diagram is fixed by the 1915 measured ice-front position. The green line to the lowerright represents the change in the position of Halley $\mathrm{V}$ with time.

- It is impossible to construct a perfectly repeating calving cycle from the data shown in the figure. It follows that the historical data does not allow us with any confidence to predict the timing of the next large calving event.

The BIS is now at its most advanced position since 1915, and the only record of the ice-front position of the SWGT being further advanced than its current position is the 1915 map (see Fig. 7). The ice front of SWGT advances by about $1 \mathrm{~km}$ each year, and within a decade the SWGT ice front will therefore be as advanced as it was in 1915.

Beside the inevitability of a large calving event happening at some point in the future on BIS, there is a high likelihood of additional calving events of smaller size happening in the near future. As described in Sect. 2, the BIS is not fully unconfined. The BIS is grounded on the McDonald Ice Rumples and the GPS (global positioning system) measurements of ice velocity, conducted by the authors as part of this BIS risk assessment in 2009, showed the ice at the top of the MIR to be stagnant. A calving event took place in the vicinity of the MIR in September 1971 (Thomas, 1973a), an iceberg approximately $30 \mathrm{~km}$ long detached from the shelf north of the MIR (Humbert and Pritchard, 2006). Currently the situation at MIR is similar to that prior to the 1970 calving event and it appears quite likely that another similarly sized calving event will take place in this area.

As a final note we point out that following a possible future calving event on the SWGT it is likely that the strain and the stress regime of the BIS will change markedly as a result (Humbert et al., 2009). SWGT and the BIS form one continuous floating ice mass and are hence mechanically coupled. Abrupt changes in the geometry of the SWGT, combined with a possible loss in side drag from the Lyddan Ice Rise, will most likely affect the flow of the BIS in some manner, but quantitative statements in this regard are difficult to make.

\subsection{Iceberg collision}

Tabular icebergs that calve from ice shelves around Antarctica frequently drift large distances in a westward direction while staying in the vicinity of the coastline. This drift is caused by the Antarctic Coastal Current (also known as the East Wind Drift Current) which flows in an anticlockwise direction around Antarctica (Fahrbach et al., 1992). A collision of an iceberg with the BIS could potentially cause a partial or full breakup of the ice shelf. A recent example of a collision of an iceberg with an ice shelf is the 2010 collision with the Mertz Ice Shelf which resulted in a large calving event (Young et al., 2010).

The BIS is naturally protected against iceberg collisions by the SWGT, which acts as a barrier to incoming icebergs arriving from the east with the Antarctic Coastal Current. Also, a 2004 swath bathymetry survey of the region discovered the existence of a $250 \mathrm{~m}$ deep plateau extending out from the ice front (see Fig. 2) - this may offer further protection from icebergs with a deep draft.

The most recent collision of an iceberg with the BIS took place in May 2010 (see Fig. 6). The collision was with the iceberg B15-K, a fragment of the world's largest observed iceberg, B15, which calved off the Ross Ice Shelf on the opposite side of Antarctica in March 2000. B15-K followed a path typical of the other six large icebergs observed over the past 3 years - in early 2010, it drifted around the SWGT and remained $50 \mathrm{~km}$ north of the BIS for several weeks. At this point the iceberg diverged from the usual drifting path of the other icebergs, and abruptly drifted south, averaging more than $10 \mathrm{~km}$ day ${ }^{1}$. As shown in Fig. 6, the iceberg passed the BIS $5 \mathrm{~km}$ to the west of the tip avoiding a direct collision. However, on 6 May 2010, the iceberg made scraping contact with the shelf close to its south-west limits and calved off a small $18 \mathrm{~km}^{2}$ portion of the ice shelf. This minor collision did not affect the structural stability of the ice shelf.

\subsection{A SWGT calving scenario with a subsequent collision with the BIS}

As mentioned previously, the SWGT prevents many icebergs from making high-velocity collisions directly into the 


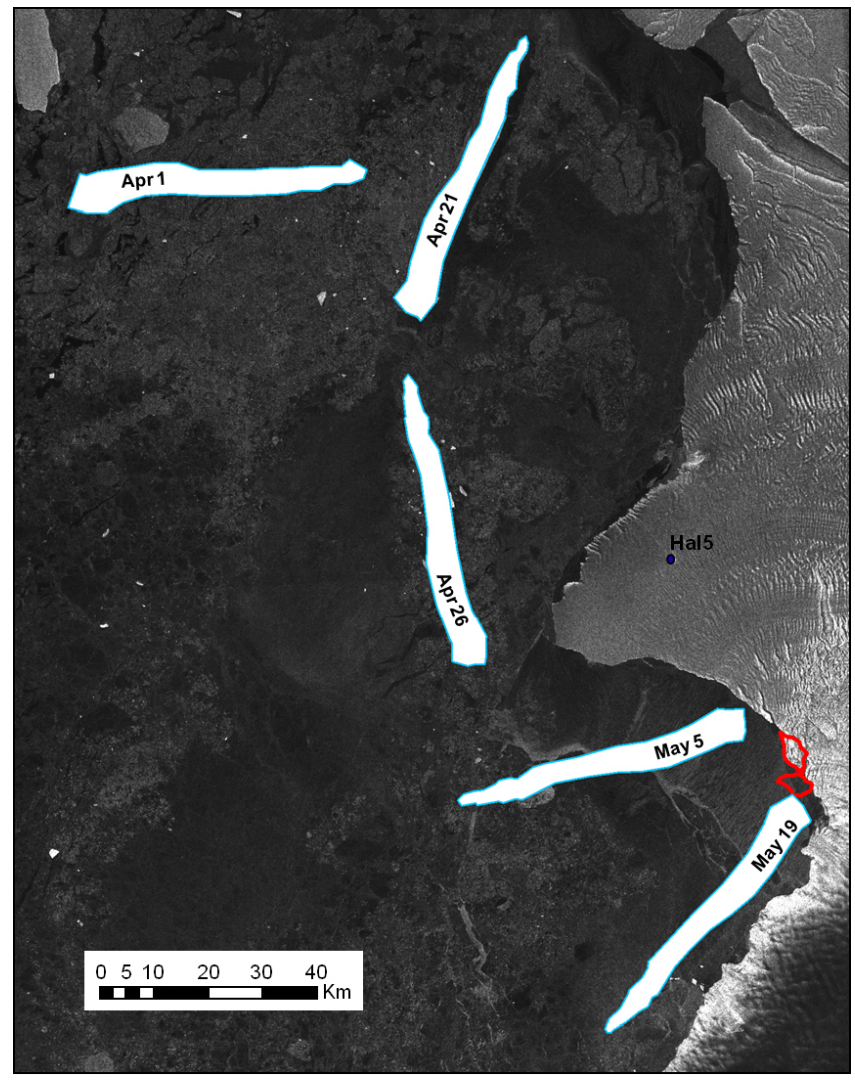

Fig. 6. The path of iceberg B-15K in early 2010 . Note the long period of minimal drifting between 1 and 21 April, and the abrupt southerly motion between 21 April and 28 April. In May, the iceberg made contact and caused an $18 \mathrm{~km}^{2}$ region of the BIS to calve off, as indicated with the outlines, lower right.

BIS. However, the SWGT itself may prove to be the greatest threat. Given its size and proximity, a calving event on SWGT could trigger a similar event on the BIS. We therefore look upon the stability of the SWGT as a critical factor affecting the safety of the Halley station, for the following three reasons.

1. Without the protection provided by the SWGT, an iceberg collision with the BIS becomes more likely.

2. The removal of the mechanical support now provided by the SWGT on the east/north-east side of the BIS can be expected to affect strain rates and stresses on the BIS, with unknown consequences.

3. A large iceberg resulting from the SWGT itself may collide with the BIS.

As the ice fronts in Fig. 7 show, the SWGT also experienced a large calving event between 1915 and 1956, and although we have no direct evidence, we cannot discount the possibility that the calving of the SWGT may have resulted in a subsequent calving of the Brunt Ice Shelf.

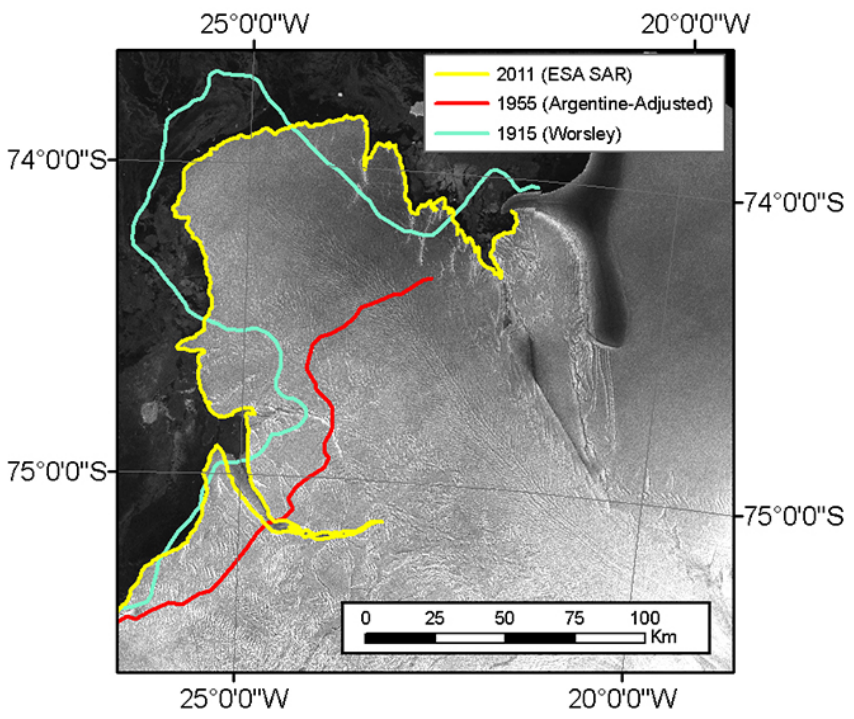

Fig. 7. Historical ice-front recordings of the SWGT. The less reliable 1955 ice front is shown here as the 1958 survey did not include SWGT.

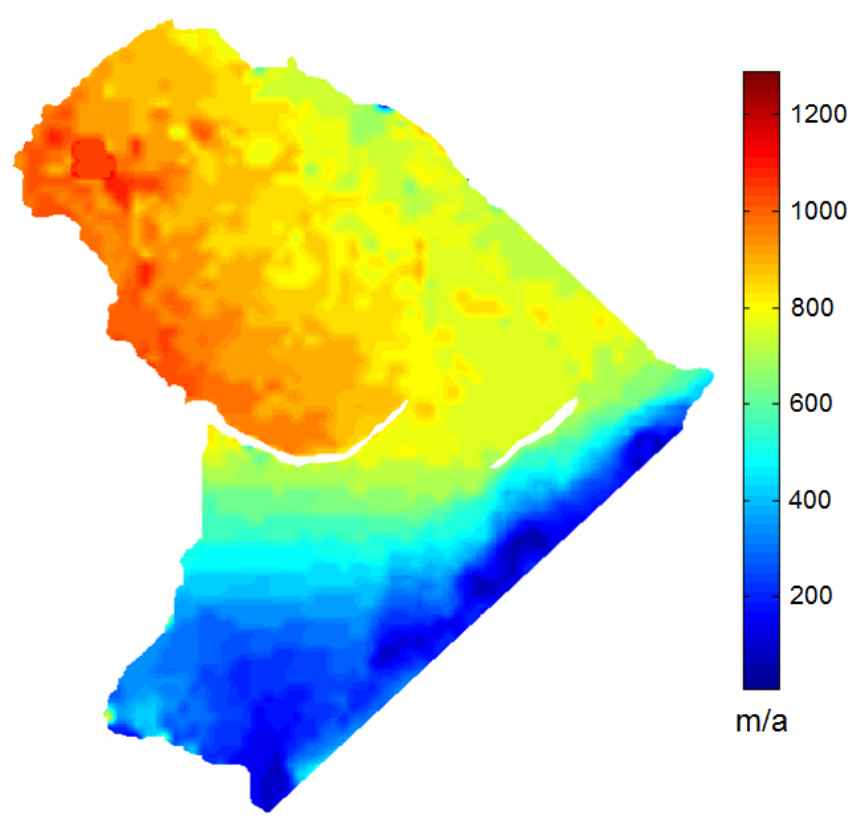

Fig. 8. Speed Profile of SWGT and the BIS. Calculated from NCC matching.

Figure 8 shows a profile of the speed of the SWGT. Speed is generally proportional to distance from the grounding line (or a support point, such as the McDonald Ice Rumples). Abrupt gradients in speed indicate the presence of active rifts. For instance, the largest speed gradient shown here is across the active Brunt-Stancomb chasm.

SWGT has three large rifts of concern. On the east side, a rift extends from the Lyddan Ice Rise south for approximately $100 \mathrm{~km}$. This rift separates the fast-moving SWGT 


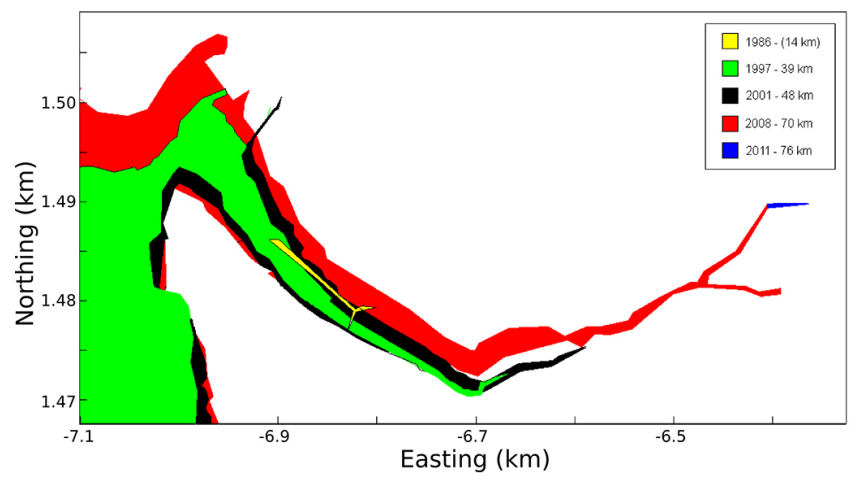

Fig. 9. The evolution of the Brunt-Stancomb chasm over time. The shape of the chasm at different times is is shown as coloured polygons. The non-coloured (white) area in the figure above and below the chasm are parts of the BIS and the SWGT, respectively. The length of the chasm, from the south promontory to the furthest visible end of the chasm in the interior, is shown in the legend of the figure.

from the much-slower Riiser-Larsen Ice Shelf to the east, and has appeared relatively stable over the last 50 years. On the south side, another $100 \mathrm{~km}$ rift runs parallel to the BIS grounding line.

The main concern is the Brunt-Stancomb chasm. Ice flow modelling of the region predicts that this rift could widen and extend further inland (Khazendar et al., 2009). By comparing Landsat photos for this rift from 1986, 1998 and 2002, and Envisat (Environmental satellite) SAR photos from 2009 and 2012, it can be seen that the rift is widening and extending (see Figs. 9 and 10). This rift in effect causes a mechanical decoupling between the fast-moving SWGT and the slower BIS flow. The crack has forked in the last 15 years, and has continued to grow in a northerly direction. If growth continues in this direction, then it will be decades before it threatens to cause a significant calving event. However, if linear growth should recommence from the southern tip of the crack and in the southerly direction, the crack would join with the southern rift by 2020 . As the crack approaches the southern rift, the dynamics of Stancomb Wills will be increasingly disconnected from those of the BIS, potentially resulting in increased strain rates and an acceleration of the growth of the crack, reducing the time frame accordingly.

If these two rifts join, then the SWGT is only hinged to the mainland by approximately $50 \mathrm{~km}$ of ice (see Fig. 11). This support is unlikely to be sufficient to anchor the entire ice shelf so a full calving event would be probable.

\section{Risk monitoring program}

Having identified the specific risk scenarios to Halley and the BIS in the previous section, we need to address the more critical questions of when and where these events may occur. We require a monitoring system to collect the data that provides these answers. Our monitoring tools are in two categories: remote sensing, and ground-based GPS stations.

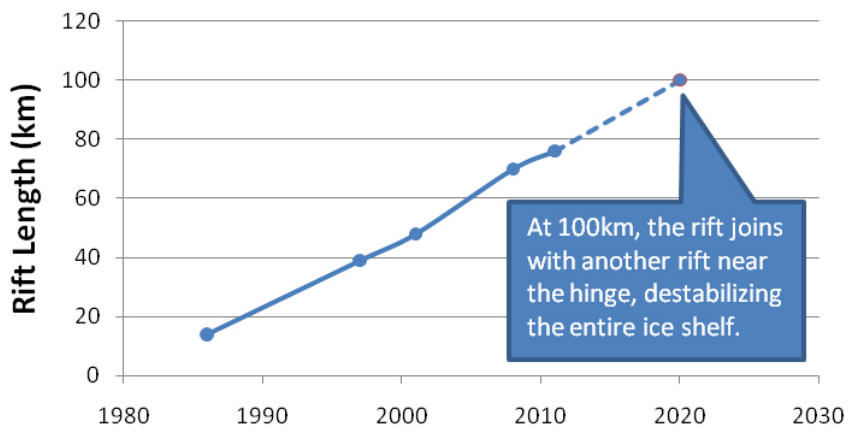

Fig. 10. The Brunt-Stancomb chasm length, extrapolated to the next rift (pictured in Fig. 11).

\subsection{Monitoring - remote sensing}

Until recently we had access to high-resolution, georegistered, SAR images from Envisat, a polar orbiting satellite operated by the European Space Agency. This resource ceased operations in 2012 and is due to be replaced in 2014 by a family of three Sentinel satellites. Here we will discuss the analyses we performed on Envisat data, which we expect to resume with the Sentinel constellation data.

\subsubsection{Velocity calculation and monitoring rift growth}

Section 3.4 described the growth of the Brunt-Stancomb chasm, detected by comparing SAR photos from Envisat. This is a critical component of the risk monitoring programme, however another way to predict rift growth before it happens is to study the velocity field of the surrounding ice shelf.

Rifts occur in regions under strain. These rifts tend to propagate in a direction normal to the maximum horizontal tensile stress. To identify such strains we require velocity maps of both ice shelves, from which we can derive the strain rates and determine which rifts are active, and if existing rifts are changing in size. We generate these velocity maps using normalised cross correlation (NCC). Also known as template matching, NCC compares a rectangular patch of one image A with an equivalent-sized patch in another image $\mathrm{B}$ and produces a value $T(x, y)$ indicating the quality of the match. This method works for any image with distinctive and robust image features that persist over time in our case, the features of a synthetic aperture radar image of the Brunt-Stancomb system are stable enough for this tracking technique. NCC is a widely used technique, in part due to it being insensitive to differences in brightness and contrast (M. Debella-Gilo, 2012). It is preferred over other techniques, such as InSAR (interferometric synthetic aperture radar), because it is still effective when the time interval between compared satellite photos is greater than a few days (Goldstein et al., 1993). 


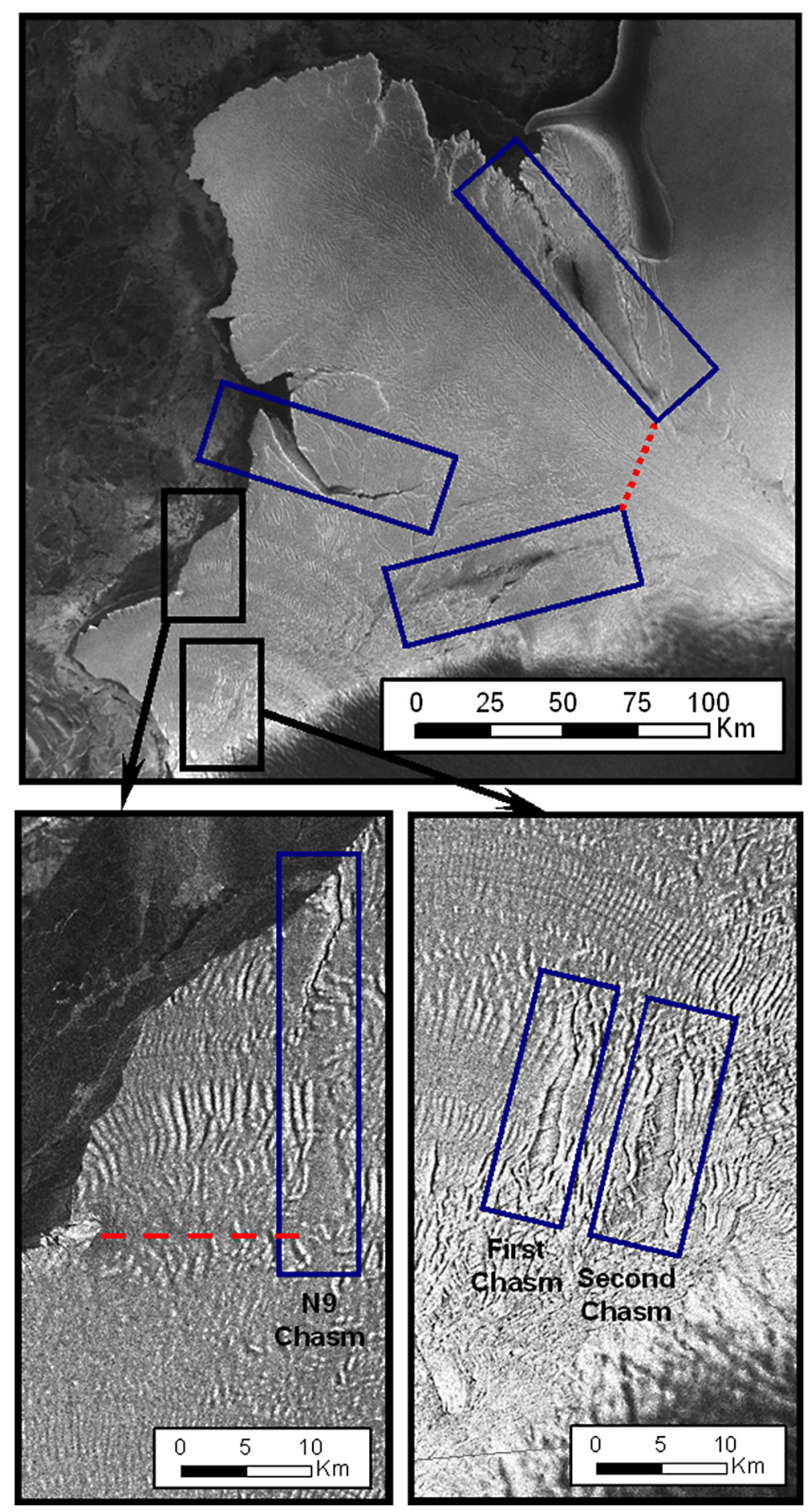

Fig. 11. Major rifts in the BIS-SWGT region. There are three large rifts in the SWGT region (discussed in Sect. 5), and three smaller dormant rifts in the BIS region, highlighted in the lower images. The dotted line in the top figure shows the shortest distance to connect two of the active rifts. The N9 Chasm, pictured lower left, may form the eastern boundary of a mini-calving event in the next decade, should weaknesses also form along the indicated dashed line.

Figure 8 shows the results of a recent velocity calculation from wide-swath SAR imagery. It shows a significant gradient not only along the two active rifts, but also in the ice mélange (Khazendar et al., 2009) between them, indicating that this region may be vulnerable to further rifts. From these data it is clear that the overall speed of the BIS is lower than that of the SWGT. The BIS is currently moving at about $470 \mathrm{~m} \mathrm{a}^{-1}$, while the main SWGT is moving at around $900 \mathrm{ma}^{-1}$.
This NCC analysis has been updated every 3-6 months during the lifetime of Envisat in order to observe strain trends that may not have yet created a visible chasm in satellite SAR images.

\subsection{GPS monitoring}

The SAR images from the previous section provide excellent spatial coverage but lack in temporal resolution. Accordingly, since 2007 we have complemented these images with data from a GPS network. With this network, we can specifically monitor the daily flexing of the BIS. Short-term strain is dominated by tidal cycles which range from hourly to monthly and are not visible in SAR data (Doake et al., 2002). If we can identify these cycles, we can subtract them from the longer-term records and velocity calculations to determine the underlying movement and detect deviations that may signal an imminent calving event. We can also detect changes in the tidal components themselves, which may indicate a change in ice shelf topography. In either case, the goal of the GPS monitoring system is to identify rifts before they become detectable in satellite imagery. Finally, if a sudden catastrophic event occurred - such as an iceberg collision our network could give us near-real-time data on the stability of the shelf to guide evacuation efforts.

Our GPS network is intended to monitor the region around the Halley station and the McDonald Ice Rumples. We have therefore deployed GPS equipment in the locations shown in Fig. 12.

We use dual frequency GPS receivers, the Leica 1200 and Trimble 5700 units, in order to get sufficient precision to measure the strain rates and tidal cycles. To obtain the level of precision required, we need to post-process the raw satellite data. (Note that double-differencing for a precise realtime kinetic match is not possible, due to the unavailability of a local static reference point). The processing of the GPS data is performed with the GPS Bernese software package. The data is processed using the precise-point positioning (PPP) technique in kinematic mode (Dach et al., 2008). To obtain the raw data from seasonally inaccessible field stations in a timely manner, we use VHF (very high frequency) radio modems (the Freewave FGR-115RC) to connect them to a controlling computer at the Halley station. A server at this location performs daily polls of the devices and downloads the raw data from each.

The GPS devices consume too much power to allow constant year-round monitoring. The devices are powered with $40 \mathrm{~W}$ solar panels and $6 \mathrm{~W}$ wind generators; however, in the mid-winter, both solar and wind is minimal. Thus, the devices will only collect $1 \mathrm{~h}$ of raw data per day throughout the winter. However, before we can make use of these data sets, we need to identify the cyclic tidal components for a continuous 28 day period of monitoring. This period can be recorded in the Antarctic summer, where $24 \mathrm{~h}$ sunlight provides sufficient power for the GPS devices. 


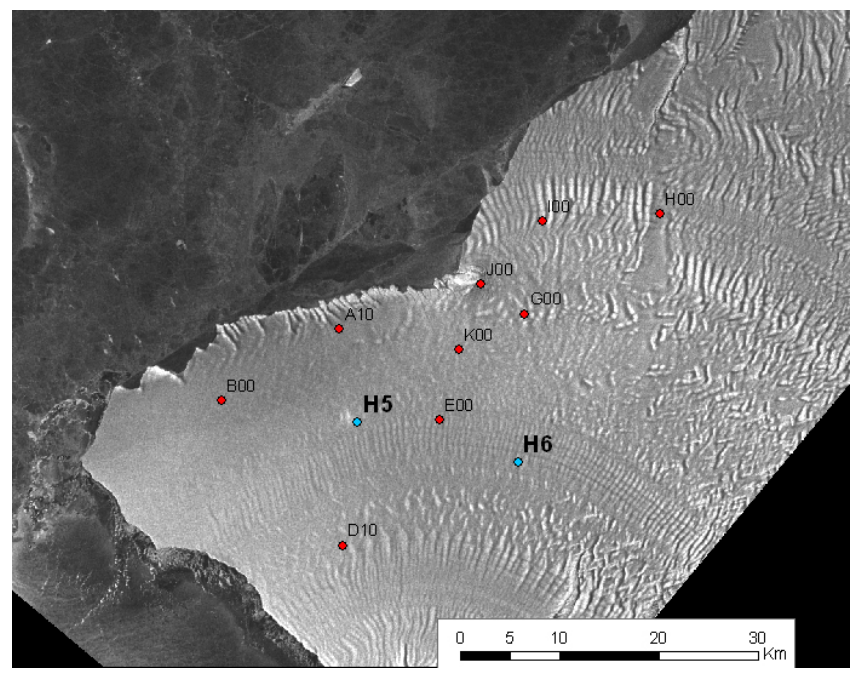

Fig. 12. Locations of the BIS real time GPS network in 2011. During the 2011/2012 season this network was moved to surround the Halley VI base.

\section{Analysis of monitoring program results}

Our remote sensing monitoring program has allowed us to monitor long-term trends and our GPS network allows us to monitor immediate threats, such as iceberg impacts or calving events that are currently in process. The primary result of our GPS stations is a series of triangles within which we can calculate strains and changes in geometry (see Fig. 13).

From Fig. 13 it is evident that there is significant strain in the ice about MIR, but that there is little strain elsewhere within the BIS. As such it is unlikely that internal strain will cause a calving event on the BIS in the near future.

\section{Conclusions}

Historical data shows that a calving event of the BIS might be imminent. In this paper, we have examined the possible scenarios in which the Halley Research Station might be put at risk by a calving event. One scenario of interest was that the BIS might calve due to its changing geometry and the resultant internal strain. However, upon looking at the cyclic ice-front data and data from our own GPS network, there is no evidence supporting this scenario. The BIS is currently stable, and the previous calving event may have had other causes. There is insufficient historical data to identify the length of a calving cycle caused by internal strain, but we do not expect it in the near future.

An alternative interpretation of the historical data is that in the period 1918-1956 the SWGT underwent a calving event and contributed to, or directly caused, the subsequent calving event on the BIS. In contrast to the BIS, the SWGT is currently much more dynamic, with several rifts that are growing at a linear rate. If this linear growth is maintained, these

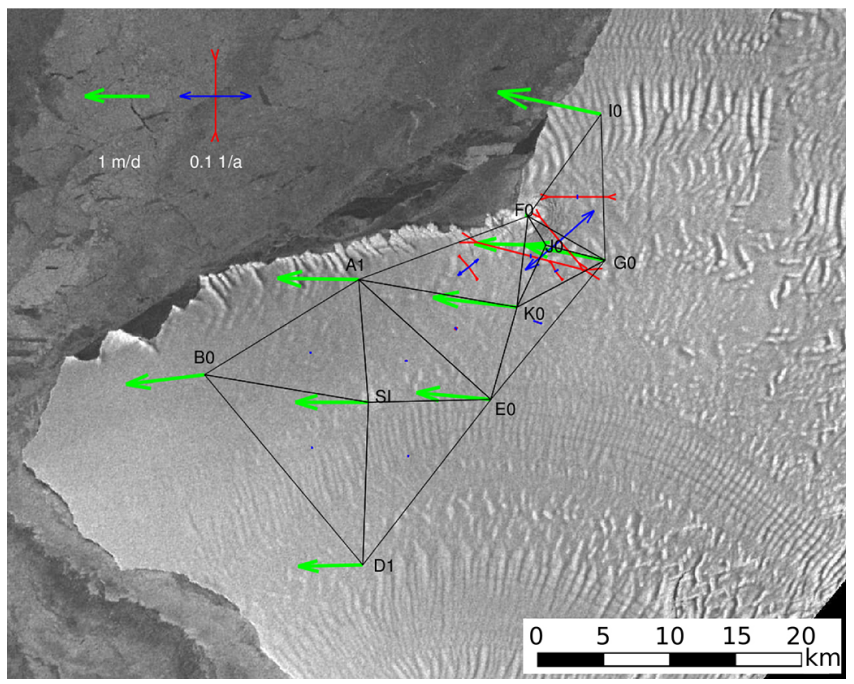

Fig. 13. Strain rates on the BIS during 2011. The green arrows show site movement, the red lines show compression rates and the blue lines show expansion rates. This analysis shows that most of the ice shelf is moving in similar directions at similar rates so there is little strain in the ice. The exception is at the near-stationary McDonald Ice Rumples (site F0), where compression and expansion occurs.

rifts could join together within 10 years and form a full calving event, which might also destabilise the BIS.

Accordingly, we believe the greatest threats to the station, in decreasing order, are the following.

\section{SWGT calving event}

Before 2020, there is a high probability that the SWGT ice shelf will have a large calving event, as evidenced by the steady advance of a rift in the west. This calving event may then destabilise the BIS in general and provoke a similar calving event there.

\section{BIS iceberg collision}

The BIS may be subject to an iceberg collision from an external iceberg, as has recently occurred with B15$\mathrm{K}$. If such an event occurred at high velocity, calving could be a rapid process. As the BIS is largely protected from icebergs by the SWGT and shallow bathymetry, this threat is a lower probability but still a general concern.

\section{BIS calving event}

The BIS itself may yet calve between the Halley station and the mainland, due to its own natural tidal flexing cycle. Velocity profiles, which show no exceptional strain in this area, indicate that this threat is a lower probability. There is no indication that such an event has yet begun. Furthermore, there is no credible calving cycle information to identify a time frame for this threat. 
To monitor these threats, we have implemented two monitoring schemes - a real-time GPS network to observe highfrequency activity on the BIS, and a satellite SAR template matching algorithm to observe long-term velocity trends on the entire SWGT region. The GPS network continues to provide short-term data on the movements and internal strains of the Brunt Ice Shelf. The satellite SAR analysis scheme ceased with the conclusion of Envisat operations, however we expect to recommence this scheme in 2014 with the launch of the Sentinel satellite constellation.

Halley $\mathrm{V}$ is now decommissioned, with all assets and individuals relocated to the safer Halley VI site. At this time, risks from a calving event have been significantly reduced, but not eliminated completely. Monitoring ice stability will remain a long-term requirement for any station built upon an ice shelf.

\section{Future work}

A real-time GPS network is needed to calculate the strains and changes in geometry of the SWGT. Prior attempts to access active areas on the SWGT for this purpose, by means of an aircraft landing and skidoo expeditions from Halley, have been prevented by the presence of large crevasse fields. The British Antarctic Survey has recently completed the development of an Aircraft Deployable Ice Observation System (ADIOS) fitted with single band GPS receivers (Jones and Gudmundsson, 2013). These sensors were then dropped from an overflying plane onto otherwise inaccessible regions of Pine Island Glacier, West Antarctica, and Scar Inlet, Antarctic Peninsula. This system should make it possible to instrument the SWGT in the future.

The effects of a SWGT calving event on the stability of the BIS is unknown. We intend to adapt the models described in Humbert and Pritchard (2006) in order to further investigate this scenario.

Acknowledgements. This study is part of the British Antarctic Survey Polar Science for Planet Earth Programme. It was funded by The Natural Environment Research Council (Grant NE/1007156/1).

Edited by: R. Lasaponara

Reviewed by: A. Khazendar and one anonymous referee

\section{References}

Banwell, A. F., MacAyeal, D. R., and Sergienk, O. V.: Breakup of the Larsen B Ice Shelf triggered by chain reaction drainage of supraglacial lakes, Geophys. Res. Lett., 40, 5872-5876, 2013.

Clark, T. D. G.: Field trip to Conos Chasm, report 1, British Antarctic Survey scientific reports, 1986a.

Clark, T. D. G.: Field trip to Monster Canyon, report 5, British Antarctic Survey scientific reports, 1986 b.
Cook, A. J. and Vaughan, D. G.: Overview of areal changes of the ice shelves on the Antarctic Peninsula over the past 50 years, The Cryosphere, 4, 77-98, doi:10.5194/tc-4-77-2010, 2010.

Dach, R., Beutler, G., and Gudmundsson, G. H.: Analysis of GPS Data from An Antarctic Ice Stream, Int. Assoc. Geodesy Symposia, 133, 569-579, 2008.

Depoorter, M. A., Bamber, J. L., Griggs, J. A., Lenaerts, J. T. M., Ligtenberg, S. R. M., van den Broeke, M. R., and Moholdt, G.: Calving fluxes and basal melt rates of Antarctic ice shelves, Nature, 502, 89-92, 2013.

Doake, C. S. M., Corr, H. F. J., Kicholls, K. W., Gaffikin, A., Jenkins, A., Bertiger, W., and King, M. A.: Tide-induced lateral movement of Brunt ice shelf, Geophys. Res. Lett., 29, 1226, doi:10.1029/2001GL014606, 2002.

Expedition, A. A.: Two unpublished Argentinian maps entitled "Mar de Weddell. Leviartamiento expeditivo efectuado pol el rompehicles A. R. A. Gral San Martin, Enero 1955”, Scott Polar Research Institute, 1955.

Fahrbach, E., Rohardt, G., and Krause, G.: The Antarctic coastal current in the southeastern Weddell Sea, Polar Biology, 12, 171$182,1992$.

Farman, J. C., Gardiner, B. G., and Shanklin, J. D.: Large losses of total ozone in Antarctica reveal seasonal ClOx/NOx interaction, Nature, 315, 207-210, 1985.

Goldstein, R. M., Engelhard, H., Kamb, B., and Frolich, R. M.: Satellite Radar Interferometry for Monitoring Ice-sheet motion: Application to an Antarctic Ice Stream, Science, 262, 15251530, 1993.

Hemmen, G. E.: Royal Society expeditions in the second half of the twentieth century, Notes and Records of the Royal Society, 2010

Holland, P. R., Corr, H. F. J., Pritchard, H. D., Vaughan, D. G., Arthern, R. J., Jenkins, A., and Tedesco, M.: The air content of Larsen Ice Shelf, Geophys. Res. Lett., 38, 10 pp. doi:10.1029/2011GL047245, 2011.

Humbert, A. and Pritchard, H. D.: Numerical simulations of the ice flow dynamics of the Brunt Ice Shelf - Stancomb Wills Ice Tongue System, Forum for Research into Ice Shelf Processes (FRISP), available at: http://nora.nerc.ac.uk/id/eprint/15742, Report. Vol. 17, University of Bergen, 2007.

Humbert, A., Thomas, K., Mohrholz, C. O., Christoph, G., Greve, R., and Lange, M. A.: A comparative modeling study of the Brunt Ice Shelf/Stancomb-Wills Ice Tongue system, East Antarctica, J. Glaciol., 55, 53-65, 2009.

IGY: International Geophysical Year map, British Antarctic Survey internal archives, 1958.

Jones, D. H. and Gudmundsson, G. H.: Aircraft Deployable Ice Observation System (ADIOS) for instrumenting inaccessible glaciers, J. Glaciol., 59, 1129-1134, 2013.

Khazendar, A., Rignot, E., and Larour, E.: Roles of marine ice, rheology, and fracture in the flow and stability of the Brunt/Stancomb-Wills Ice Shelf, J. Geophys. Res., 114, F04007, doi:10.1029/2008JF001124, 2009.

King, J. C., Anderson, P. S., M., C. S., and Mobbs, S. D.: The surface energy and mass balance at Halley, Antarctica during winter, J. Geophys. Res., 101, 19119-19128, 1996.

Lange, M. A. and Kohnen, H.: Ice front fluctuations in the Eastern and Southern Weddell Sea, Ann. Glaciol., 6, 187-191, 1985. 
Limbert, D. W. S.: The Absolute and Relative Movement, and Regime of the Brunt Ice Shelf near Halley Bay, British Antarctic Survey Bulletin, 3, 1-11, 1964.

M. Debella-Gilo, A. K.: Measurement of surface displacement and deformation of mass movements using least squares matching of repeat high resolution satellite and aerial images, Remote Sens., 4, 43-67, 2012.

Rack, W. and Rott, H.: Pattern of retreat and disintegration of the Larsen B ice shelf, Antarctic Peninsula, Ann. Glaciol., 39, 505510, 2004.

Shackleton, E.: South: The story of Shackleton's 1914-17 expedition, 1st Edn., 1919.

Simmons, D. A. and Rouse, J. R.: Accelerating flow of the Brunt Ice Shelf, Antarctica, J. Glaciol., 30, 377-380, 1984.
Thomas, R.: The dynamics of the Brunt Ice Shelf, Coats Land, Antarctica, AD6/17/SR/79, British Antarctic Survey, 1973a.

Thomas, R. H.: The dynamics of the Brunt Ice Shelf, Coats Land, Antarctica, British Antarctic Survey Scientific Report, 279-381, $1973 b$.

Turner, J. and Colwell, S. R.: The SCAR READER project: Towards a high-quality database of mean Antarctic meteorological observations, J. Climate, 17, 2890-2898, 2004.

Worsely, F.: Track of Endurance 1914-15 in the Weddell Sea, Sketch Survey Map C8421, archived at United Kingdom Hydrographic Office, 1921.

Young, N., Legresy, B., Coleman, R., and Massom, R.: Mertz Glacier Tongue unhinged by Giant Iceberg, Austr. Antarctic Magazine, 18, 19, 2010. 